\title{
PTP1B Inhibition Causes Rac1 Activation by Enhancing Receptor Tyrosine Kinase Signaling
}

\author{
Ayako Tsuchiyaa ${ }^{\mathrm{a}, \mathrm{d}}$ Takeshi Kanno ${ }^{\mathrm{a}, \mathrm{d}}$ Hisao Nagaya ${ }^{\mathrm{b}}$ Tadashi Shimizu \\ Akito Tanakac Tomoyuki Nishizakia \\ aDivision of Bioinformation, Department of Physiology, Hyogo College of Medicine, Nishinomiya, \\ bLaboratory of Cell and Gene Therapy, Institute for Advanced Medical Sciences, Hyogo College of \\ Medicine, Nishinomiya, 'Laboratory of Chemical Biology, Advanced Medicinal Research Center, Hyogo \\ University of Health Sciences, Kobe, Japan; ${ }^{\mathrm{d} A}$. Tsuchiya and T. Kanno contributed equally to this work
}

\section{Key Words}

Protein tyrosine phosphatase 1B - Phosphatidylinositol 3 kinase - 3-Phosphoinositidedependent protein kinase-1 $\bullet$ Akt $\bullet$ Rac1

\begin{abstract}
Background/Aims: The present study investigated the signaling pathway underlying Rac1 activation induced by the linoleic acid derivative 8-[2-(2-pentyl-cyclopropylmethyl)cyclopropyl]-octanoic acid (DCP-LA). Methods: Activity of protein tyrosine phosphatase 1B (PTP1B) was assayed under cell-free conditions. Western blot was carried out to quantify phosphorylation of insulin receptor substrate-1 (IRS-1) and Akt in PC-12 cells. Rac1 activity was monitored in the föerster resonance energy transfer (FRET) analysis using living and fixed PC-12 cells. Results: DCP-LA markedly suppressed PTP1B activity in a concentration (100 pM-100 $\mu \mathrm{M}$ )-dependent manner. In the DCP-LA binding assay, fluorescein-conjugated DCPLA produced a single fluorescent signal band at $60 \mathrm{kDa}$, corresponding to the molecule of PTP1B, and the signal was attenuated or abolished by co-treatment or pretreatment with nonconjugated DCP-LA. DCP-LA significantly enhanced nerve growth factor (NGF)-stimulated phosphorylation of IRS-1 at Tyr1222 and Akt1/2 at Thr308/309 and Ser473/474 in PC-12 cells. In the FRET analysis, DCP-LA significantly enhanced NGF-stimulated Rac1 activation, which is abrogated by the phosphatidylinositol 3 kinase (PI3K) inhibitor wortmannin, the 3-phosphoinositide-dependent protein kinase-1 (PDK1) inhibitor BX912, or the Akt inhibitor MK2206. Conclusion: The results of the present study show that DCP-LA-induced PTP1B inhibition, possibly through its direct binding, causes Racl activation by enhancing a pathway along a receptor tyrosine kinase (RTK)/IRS-1/PI3K/Akt/Rac1 axis.
\end{abstract}

Copyright (C) 2014 S. Karger AG, Basel 


\section{Introduction}

8-[2-(2-Pentyl-cyclopropylmethyl)-cyclopropyl]-octanoic acid (DCP-LA), a synthesized linoleic acid derivative, serves as a selective activator of protein kinase $\mathrm{C} \varepsilon(\mathrm{PKC} \varepsilon)[1,2]$. DCP-LA-induced PKC $\varepsilon$ activation causes an enhancement in the activity of presynaptic $\alpha 7$ acetylcholine $(\mathrm{ACh})$ receptors, to stimulate presynaptic glutamate release and facilitate hippocampal synaptic transmission [3,4]. The DCP-LA action may be responsible for improvement of spatial learning and memory disorders induced by intraperitoneal injection with scopolamine or intraventricular injection with amyloid $\beta_{1-40}$ peptide [5] and improvement of age-related cognitive decline [6]. A considerably low dose of mutant amyloid $\beta_{1-42}$ peptide lacking glutamate- 22 suppresses expression of long-term potentiation (LTP), a cellular model of learning and memory, and DCP-LA neutralizes the impaired LTP [7], suggesting the beneficial effect of DCP-LA on Alzheimer's dementia.

DCP-LA, on the other hand, activates $\mathrm{Ca}^{2+} /$ calmodulin-dependent protein kinase II (CaMKII) by inhibiting protein phosphatase 1 (PP1), to promote exocytosis of the $\alpha$-amino3-hydroxy-5-methyl-4-isoxazole propionic acid (AMPA) receptor subunits GluR1 and GluR2 and to increase localization of AMPA receptors on the postsynaptic plasma membrane in the hippocampus [8]. Then, we postulated that DCP-LA might interact with other protein phosphatases in addition to PP1.

In the present study, we assayed activity of protein tyrosine phosphatase 1B (PTP1B) and examined DCP-LA binding to PTP1B using a fluorescein-conjugated DCP-LA in cell-free systems; we quantified tyrosine phosphorylation of receptor tyrosine kinase (RTK), insulin receptor substrate 1 (IRS-1), and Akt1/2 in PC-12 cells; we monitored Rac1 activity using a plasmid encoded föerster resonance energy transfer (FRET) probe in PC-12 cells. We show here that DCP-LA-induced PTP1B inhibition through its direct binding allows to activate Rac1 by enhancing a pathway along a RTK/IRS-1/phosphatidylinositol 3 kinase (PI3K)/3phosphoinositide-dependent protein kinase-1 (PDK1)/Akt/Rac1 axis.

\section{Materials and Methods}

\section{Assay of PTP1B activity}

PTP1B activity was monitored in a cell-free system by the method previously described [9]. Human PTP1B was cloned into pGEX-6P-3 vector with a GST tag at the $\mathrm{NH}_{2}$ terminus, and expressed in competent $E$. coli BL21 (DE3), suitable for transformation and protein expression. GST-fusion PTP1B was affinity-purified using Glutathione Sepharose 4B (GE Healthcare, Piscataway, NJ, USA). PTP1B (1 $\mu \mathrm{g} /$ well) was preincubated at $37^{\circ} \mathrm{C}$ for $30 \mathrm{~min}$ in a reaction medium (50 mM HEPES, $1 \mathrm{mM}$ EDTA, $50 \mathrm{mM} \mathrm{NaCl}$, and $1 \mathrm{mM}$ dithiothreitol, $\mathrm{pH} 7.2)$ in the presence and absence of sodium orthovanadate $\left(\mathrm{Na}_{3} \mathrm{VO}_{4}\right)$, DCP-LA, or linoleic acid. Then, p-nitrophenyl phosphate (pNPP)(10 mM)(Sigma-Aldrich, St. Louis, MO, USA) as a substrate was added to the reaction medium followed by 60 -min incubation, and the reaction was terminated by adding $0.1 \mathrm{~N}$ $\mathrm{NaOH}$. Dephosphorylated pNPP was quantified at an absorbance of $405 \mathrm{~nm}$ with a SpectraMax PLUS384 (Molecular Devices, Sunnyvale, CA, USA).

\section{Synthesis of fluorescein-conjugated DCP-LA}

1-Ethyl-3-[3-dimethylaminopropyl]-carbodiimide hydrochloride $(15 \mathrm{mg}, 0.078 \mathrm{mmol})$ and 4-dimethylaminopyridine $(7.1 \mathrm{mg}, 0.058 \mathrm{mmol}$ ) were added to a solution containing DCP-LA (20 mg, 0.065 mmol) and 5-aminofluorescein (25 mg, $0.071 \mathrm{mmol})$ in $\mathrm{CH}_{2} \mathrm{Cl}_{2}(1 \mathrm{ml})$ under ice-cooling. The mixture was stirred for $12 \mathrm{~h}$ at room temperature and then, water was added. The aqueous layer was extracted with ethyl acetate, and the combined organic layers were dried over anhydrous $\mathrm{MgSO}_{4}$, and concentrated under reduced pressure. The crude product was purified by silica gel column chromatography (hexane:ethyl acetate $=4: 1)$ to give the desired compound $(14 \mathrm{mg}, 50 \%)$ as an orange solid. ${ }^{1} \mathrm{H}-\mathrm{NMR}\left(400 \mathrm{MHz}, \mathrm{CDCl}_{3}\right): \mathrm{d}$ $-0.35--0.21(\mathrm{~m}, 2 \mathrm{H}), 0.55-0.85(\mathrm{~m} 6 \mathrm{H}), 0.88(\mathrm{t}, J=7.3 \mathrm{~Hz}, 3 \mathrm{H}), 0.95-1.55(\mathrm{~m}, 20 \mathrm{H}), 1.75(\mathrm{dt}, J=7.3$ and 7.3 $\mathrm{Hz}, 2 \mathrm{H}), 2.57$ (t, J = 7.8 Hz, 2H), 3.90-4.10 (br s, 1H), 6.15-6.45 (br s, 1H), 6.50 (dd, $J=7.8$ and $1.8 \mathrm{~Hz}, 1 \mathrm{H}$ ), 
$6.66(\mathrm{~s}, 1 \mathrm{H}), 6.67(\mathrm{~d}, J=7.8 \mathrm{~Hz}, 1 \mathrm{H}), 6.75(\mathrm{dd}, J=8.2$ and $2.3 \mathrm{~Hz}, 1 \mathrm{H}), 6.85(\mathrm{~d}, J=8.2 \mathrm{~Hz}, 1 \mathrm{H}), 6.86(\mathrm{~d}, J=9.1$ $\mathrm{Hz}, 1 \mathrm{H}), 6.93(\mathrm{dd}, J=9.1$ and $1.8 \mathrm{~Hz}, 1 \mathrm{H}), 7.03(\mathrm{~d}, J=2.3 \mathrm{~Hz}, 1 \mathrm{H}), 7.18(\mathrm{~d}, J=1.8 \mathrm{~Hz}, 1 \mathrm{H})$; ESI-HRMS (negative ion, sodium formate) calculated for $\left.\mathrm{C}_{40} \mathrm{H}_{46} \mathrm{NO}_{6}([\mathrm{M}-\mathrm{H}]]^{-}\right) 636.3331$; found 636.3352.

\section{DCP-LA binding assay to PTP1B}

PTP1B was separated by blue native-polyacrylamide gel electrophoresis (PAGE). PTP1B was dissolved in a sample buffer [ $50 \mathrm{mM}$ immidazole, $50 \mathrm{mM} \mathrm{NaCl}, 5 \mathrm{mM}$ 6-aminohexanoic acid, $40 \%$ (v/v) glycerol, $0.5 \%$ (w/v) Coomassie G-250 and 1\% (w/v) digitonin, pH 7.0], and electrophoresed onto a TGX Gel (BioRad, Hercules, CA, USA) in a cathode buffer [50 mM Tricine, $7.5 \mathrm{mM}$ imidazole, and $0.02 \%$ (w/v) Coomassie G-250, pH 7.0] and an anode buffer (25 mM imidazole, pH 7.0). After pretreatment with or without $1 \mathrm{mM}$ non-conjugated DCP-LA at $37{ }^{\circ} \mathrm{C}$ for $30 \mathrm{~min}$, gels were reacted with $1 \mathrm{mM}$ fluorescein-conjugated DCP-LA in the presence and absence of $1 \mathrm{mM}$ non-conjugated DCP-LA at $37^{\circ} \mathrm{C}$ for $60 \mathrm{~min}$. Fluorescent signals were visualized using FluoroPhoreStar3000 (Anatech, Tokyo, Japan).

\section{Cell culture}

PC-12 cells, obtained from RIKEN Cell Bank (Tsukuba, Japan), were cultured in Dulbecco's modified Eagle's medium (DMEM) with 10\% (v/v) heat-inactivated fetal bovine serum (FBS) and 10\% (v/v) heatinactivated horse serum, supplemented with penicillin $(100 \mathrm{U} / \mathrm{ml})$, and streptomycin $(0.1 \mathrm{mg} / \mathrm{ml})$, in a humidified atmosphere of $5 \% \mathrm{CO}_{2}$ and $95 \%$ air at $37^{\circ} \mathrm{C}$.

\section{Western blotting}

PC-12 cells were treated with nerve growth factor (NGF) and/or DCP-LA, and then lysed in a lysate solution [150 mM NaCl, $20 \mathrm{mM}$ Tris, $0.1 \%$ (v/v) Tween-20 and $0.1 \%$ (w/v) sodium dodecyl sulfate (SDS), pH 7.5] containing $1 \%(\mathrm{v} / \mathrm{v})$ protease inhibitor cocktail and $1 \%(\mathrm{v} / \mathrm{v})$ phosphatase inhibitor cocktail (Nacalai Tesque, Kyoto, Japan). The lysates were centrifuged at $800 \mathrm{~g}$ for $5 \mathrm{~min}$ at $4{ }^{\circ} \mathrm{C}$. Proteins were separated by SDS-PAGE and then transferred to polyvinylidene difluoride (PVDF) membranes. Blotting membranes were blocked with TBS-T [150 mM NaCl, 0.1\% (v/v) Tween-20 and $20 \mathrm{mM}$ Tris, pH 7.5] containing 5\% (w/v) bovine serum albumin and subsequently reacted with antibodies against phospho-Tyr490-TrkA (pY490) (Cell Signaling Technology, Inc., Danvers, MA, USA), TrkA (Cell Signaling Technology), phospho-Tyr1222IRS-1 (pY1222)(Cell Signaling Technology), IRS-1 (Santa Cruz Biotechnology, Inc., Dallas, Texas, USA), phospho-Thr308/309-Akt1/2 (pT308/309)(Cell Signaling Technology), phospho-Ser473/474-Akt1/2 (pS473/474) (Cell Signaling Technology), and Akt1/2 (Cell Signaling Technology). After washing, membranes were reacted with a horseradish peroxidase-conjugated goat anti-rabbit IgG antibody. Immunoreactivity was detected with an ECL kit (Invitrogen, Carlsbad, CA, USA) and visualized using a chemiluminescence detection system (GE healthcare). Protein concentrations for each sample were determined with a BCA protein assay kit (Thermo Fisher Scientific, Waltham, MA, USA).

\section{Monitoring of Rac1 activity}

FRET probe containing Raichu-Rac1 with EV linker was kindly gifted from Dr. Matsuda (Kyoto university)[10, 11]. PC-12 cells were transfected with the FRET probe using an X-tremeGENE HP DNA transfection reagent (Roche, Mannheim, Germany). Twenty-four h after transfection fluorescent signals in living cells were monitored at 474-nm argon laser for cyan fluorescent protein (CFP) and 506-nm argon laser for yellow fluorescent protein (YFP) with a Zeiss LSM510 META inverted microscope (Oberkochen, Germany) before and after bath-application with sodium orthovanadate $\left(\mathrm{Na}_{3} \mathrm{VO}_{4}\right)$ or NGF and/or DCP-LA. In a different set of experiments, cells were untreated and treated with NGF and/or DCP-LA in the presence and absence of inhibitors for $30 \mathrm{~min}$, and then fixed with formaldehyde [final conc. 3.7\% (v/v)]. Then, CFP and YFP signals were monitored. The background was subtracted and the FRET ratio (YFP signal intensity/ CFP signal intensity) was calculated using an ImageJ software (National Institutes of Health, USA).

\section{Statistical analysis}

The data presented were mean \pm standard error of the mean (SEM). Statistical differences were analyzed by Dunnett's test and unpaired $t$-test. Values of $p<0.05$ were considered statistically significant. 
Fig. 1. Effect of DCP-LA on PTP1B activity. PTP1B was reacted with pNPP in the presence and absence of sodium orthovanadate $\left(\mathrm{Na}_{3} \mathrm{VO}_{4}\right)$, DCP-LA, or linoleic acid (LA) at concentrations as indicated, and dephosphorylated pNPP was quantified. In the graph, each value represents the mean ( \pm SEM) percentage of basal phosphatase activity (control)( $\mathrm{n}=4-8$ independent experiments). ${ }^{* *} P<0.001,{ }^{* * *} P<0.0001$ as compared with control, Dunnett's test.

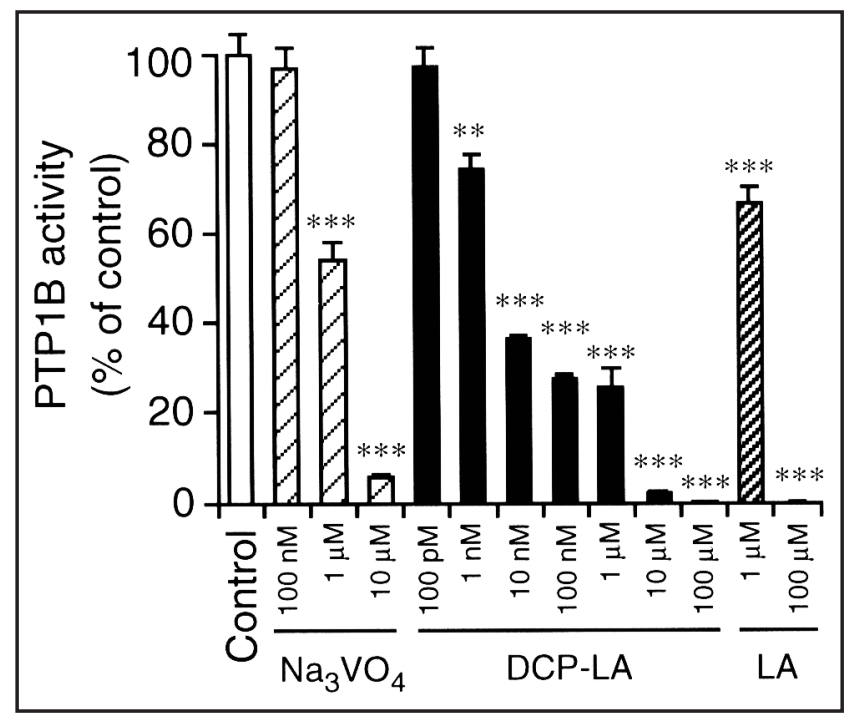

\section{Results}

DCP-LA suppresses PTP1B activity, possibly through its direct binding

We initially examined the effect of DCP-LA on PTP1B activity in a cell-free system. In the PTP1B assay, sodium orthovanadate $\left(\mathrm{Na}_{3} \mathrm{VO}_{4}\right)$, an inhibitor of PTP1B, reduced PTP1B activity in a concentration (0.1-10 $\mu \mathrm{M})$-dependent manner (Fig. 1), confirming a reliable PTP1B assay. DCP-LA significantly reduced PTP1B activity in a concentration (100 pM-100 $\mu \mathrm{M}$ )-dependent manner, reaching almost $0 \%$ of control levels at $100 \mu \mathrm{M}$ (Fig. 1). Likewise, the cis-unsaturated free fatty acid linoleic acid also reduced PTP1B activity in a concentration (1-100 $\mu \mathrm{M}$ )-dependent manner (Fig. 1).

We subsequently examined interaction of DCP-LA with PTP1B using a fluoresceinconjugated DCP-LA (Fig. 2A). Fluorescein-conjugated DCP-LA produced a single fluorescent signal band at $60 \mathrm{kDa}$ in a mixture sample with PTP1B, which corresponds to the molecule of PTP1B, and the signal was attenuated or abolished by co-treatment or pretreatment with non-conjugated DCP-LA (Fig. 2B). This suggests that DCP-LA directly binds to PTP1B. Taken together, these results indicate that DCP-LA suppresses PTP1B activity, possibly through its direct binding.

\section{DCP-LA enhances TrkA signaling}

When activated, RTK phosphorylates its own receptor and IRS- 1 at the tyrosine residue, and PTP1B dephosphorylates tyrosine phosphorylation of those proteins. PTP1B inhibition, accordingly, could enhance RTK signal as a result of persistent phosphorylation of the receptor and IRS-1. NGF (10 ng/mL) significantly enhanced phosphorylation of TrkA at Tyr490, a receptor for NGF, but unexpectedly, no further enhancement was obtained by adding DCPLA (100 nM)(Fig. 3A). NGF had little effect on phosphorylation of IRS-1 at Tyr1222 at concentrations ranging from 1 to $100 \mathrm{ng} / \mathrm{mL}$ in PC-12 cells, but Tyr1222 phosphorylation was significantly enhanced in the presence of DCP-LA (100 nM)(Fig. 3B). This suggests that DCP-LA enhances TrkA signaling in association with PTP1B inhibition.

\section{DCP-LA enhances NGF-stimulated Akt activation}

Akt is activated through a RTK/IRS-1/PI3K/PDK1/Akt pathway $[12,13]$. Activated RTK phosphorylates its own receptor and IRS-1, to dissociate IRS from the receptor and activate PI3K. Activated PI3K produces phosphatidylinositol $(3,4,5)$-triphosphate $\left[\mathrm{PI}(3,4,5) \mathrm{P}_{3}\right]$ by phosphorylating phosphatidylinositol 4,5-bisphosphate $\left[\mathrm{PI}(4,5) \mathrm{P}_{2}\right]$, and in turn, $\mathrm{PI}(3,4,5)$ $\mathrm{P}_{3}$ activates PDK1 through its binding. Then, Akt is activated by PI3K and PDK1. If DCP-LA 


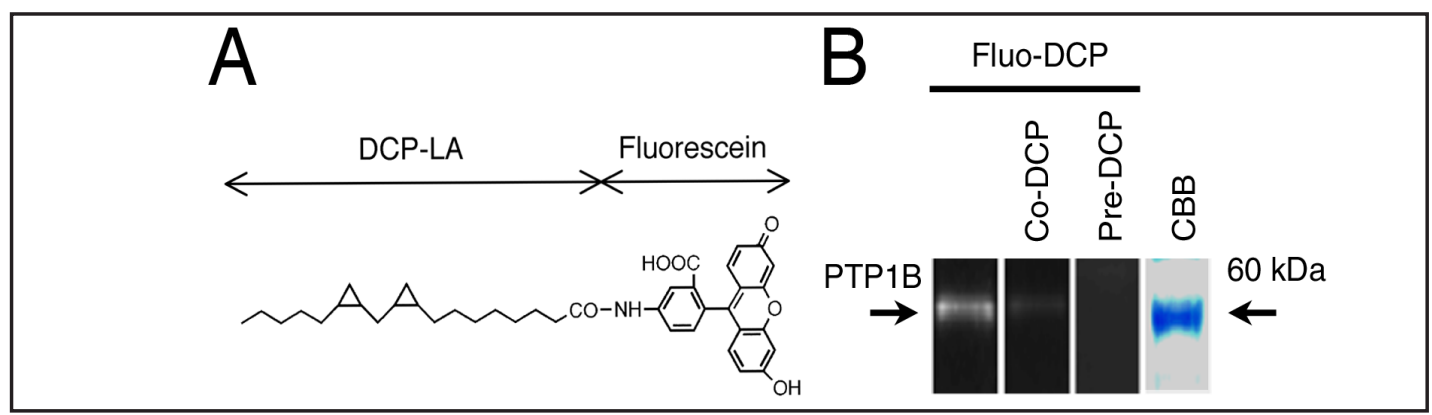

Fig. 2. DCP-LA binding to PTP1B. (A) Chemical structure for fluorescein-conjugated DCP-LA. Electrophoresed PTP1B (B) was incubated with fluorescein-conjugated DCP-LA (Fluo-DCP)(1 mM), and fluorescent signals were detected ( $\mathrm{n}=4$ independent experiments). Co-DCP, co-treatment with non-conjugated DCP-LA (1 $\mathrm{mM}$ ); Pre-DCP, pretreatment with non-conjugated DCP-LA (1 mM); CBB, Coomassie brilliant blue staining.

Fig. 3. Effect of DCP-LA on tyrosine phosphorylation of TrkA, IRS-1, and Akt1/2 in PC-12 cells. Cells were untreated and treated with NGF at concentrations as indicated and/or DCP-LA (100 nM) for $10 \mathrm{~min}$ followed by Western blotting using antibodies against pY490, TrkA, pY1222, IRS-1, pT308/309, pS473/474, and Akt1/2. Signal intensities for phosphorylation of each protein were normalized by those for total proteins. (A) In the graph, each column represents the mean $( \pm$ SEM) normalized intensity for pY490 (n=4 independent experiments). $N S$, not significant. $P$ values, unpaired $t$-test. (B) In the graph, each column represents the mean $( \pm$ SEM) normalized intensity for pY1222 (n=4 independent experiments). $P$ values, Dunnett's test. (C) In the graphs, each column represents the mean $( \pm$ SEM) normalized intensity for pT308/309 and pS473/474 (n=4 independent experiments). $P$ values, unpaired $t$-test.

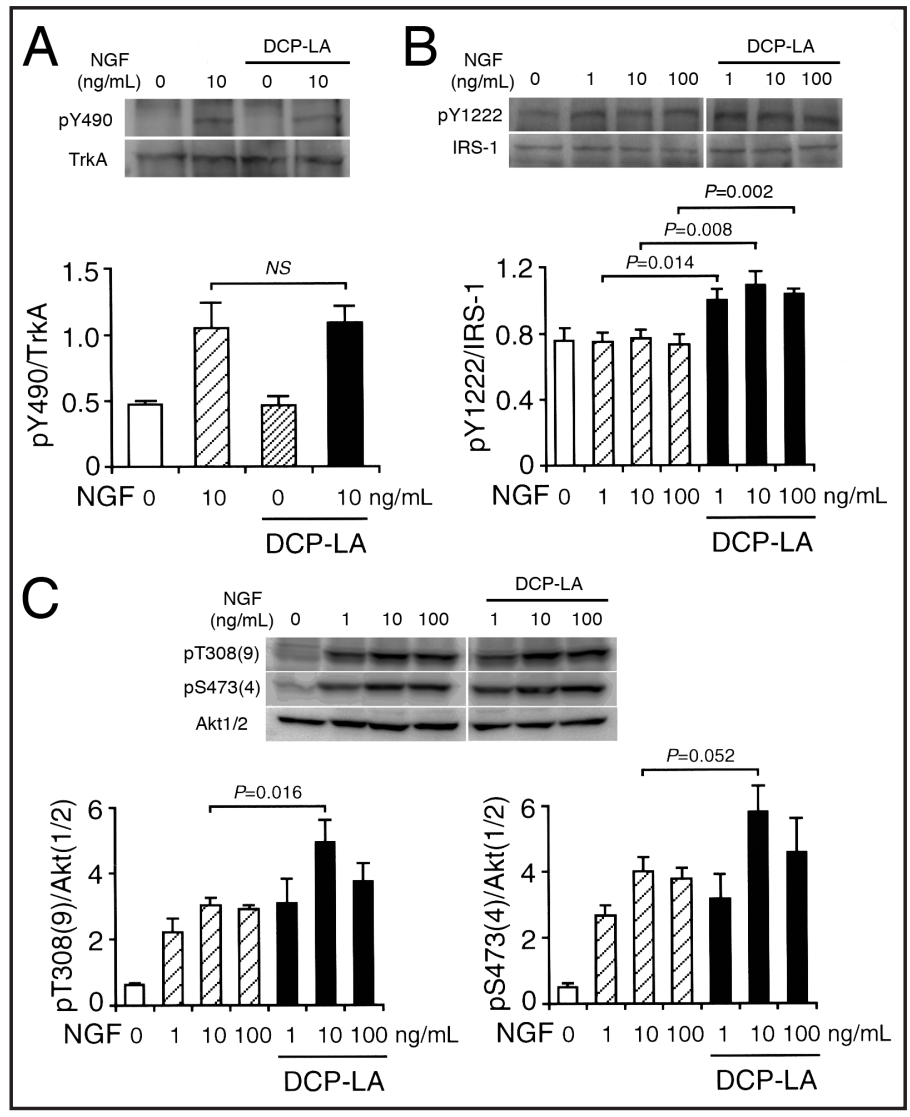

enhances TrkA signaling, then the agent could enhance NGF-stimulated Akt activation. To obtain evidence for this, we monitored phosphorylation of Akt1/2 in PC- 12 cells.

NGF significantly increased phosphorylation of Akt1/2 at Thr308/309 and Ser473/474 at concentrations ranging from 1 to $100 \mathrm{ng} / \mathrm{mL}$ in PC-12 cells, and DCP-LA (100 nM) further increased NGF (10 ng/mL)-stimulated phosphorylation of Akt1/2 (Fig. 3C). This indicates that DCP-LA enhances NGF-induced Akt1/2 activation.

\section{DCP-LA stimulates/enhances Rac1 activation}

The small G-protein Rac1 is activated as a downstream target of Akt [12,13]. We finally examined whether DCP-LA enhances NGF-induced Rac1 activation in PC-12 cells using a FRET probe. In the FRET analysis, an increase and a decrease in the ratio (YFP signal intensity/ 
Fig. 4. DCP-LAinduced Rac1 activation. FRET monitoring was carried out in living and fixed PC-12 cells, and the FRET ratio (YFP signal intensity/CFP signal intensity) was calculated. (A) Living cell monitoring. Cells were treated with NGF (10 ng/mL) and/or DCP-LA (100 nM). The FRET ratio images are shown in the upper panel and time-course FRET ratio profiles are shown in the lower panel. DMSO, dimethyl sulfoxide. Scale bars, $5 \mu \mathrm{m}$. Note that a similar result was obtained with 5 independent experiments. (B) Fixed cell monitoring. Cells were untreated (Control)

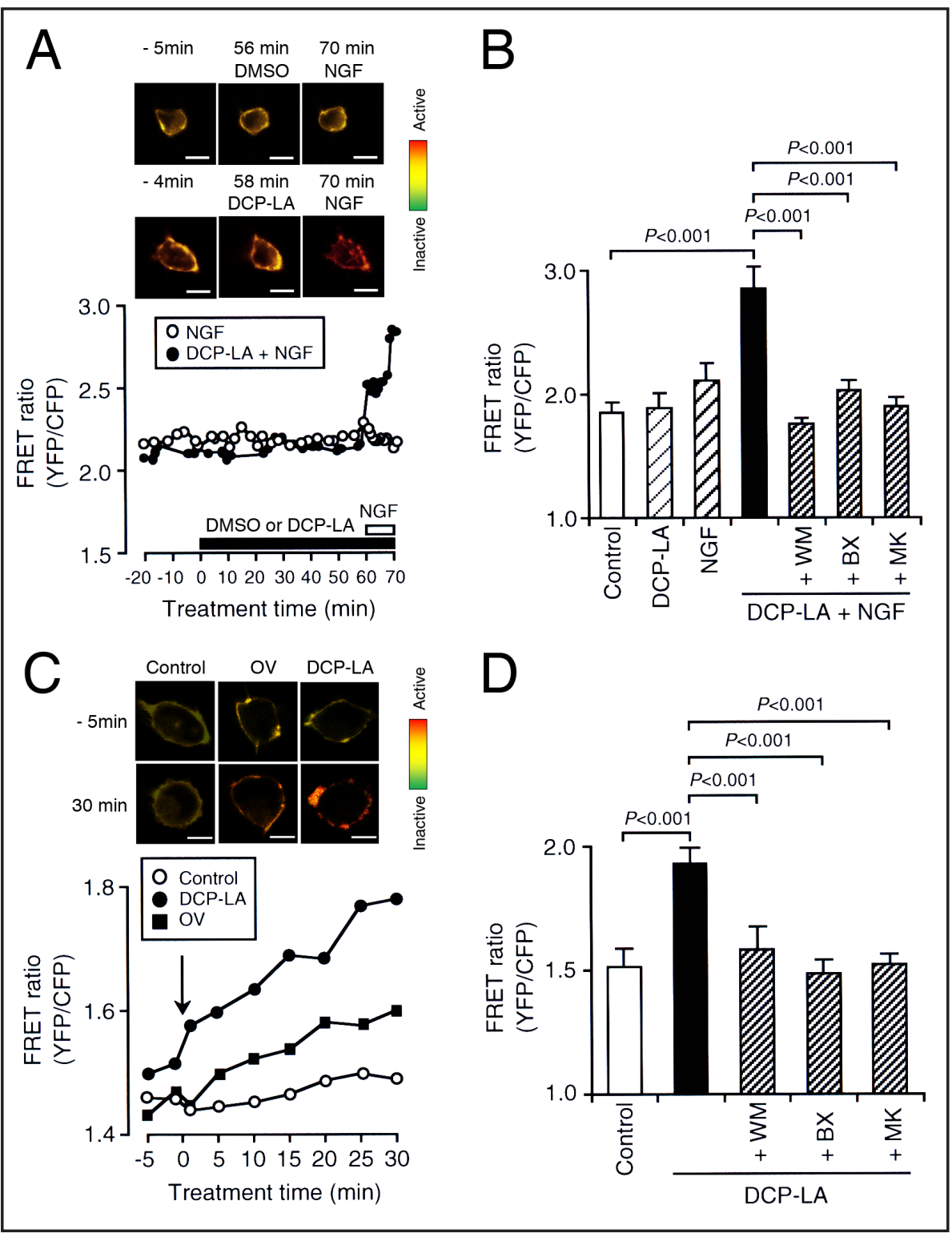

and treated with NGF $(10 \mathrm{ng} / \mathrm{mL})$ and/or DCP-LA $(100 \mathrm{nM})$ in the presence and absence of wortmannin (WM)(20 nM), BX912 (BX)(100 nM), or MK2206 (MK)(5 $\mu \mathrm{M})$ for $30 \mathrm{~min}$, and then fixed. In the graph, each column represents the mean ( \pm SEM) FRET ratio ( $\mathrm{n}=9-14$ independent experiments). $P$ values, Dunnett's test. (C) Living cell monitoring. Cells were untreated (Control) and treated with DCP-LA (10 $\mu \mathrm{M})$ or sodium orthovanadate $(\mathrm{OV})(10 \mu \mathrm{M})$. The FRET ratio images are shown in the upper panel and time-course FRET ratio profiles are shown in the lower panel. Scale bars, $5 \mu \mathrm{m}$. Note that a similar result was obtained with 3 independent experiments. (D) Fixed cell monitoring. Cells were untreated (Control) and treated with DCPLA $(10 \mu \mathrm{M})$ in the presence and absence of wortmannin (WM)(20 nM), BX912 (BX)(100 nM), or MK2206 $(\mathrm{MK})(5 \mu \mathrm{M})$ for $30 \mathrm{~min}$. In the graph, each column represents the mean $( \pm$ SEM) FRET ratio ( $\mathrm{n}=5-12$ independent experiments). $P$ values, Dunnett's test.

CFP signal intensity) correspond to activation and inactivation of Rac1, respectively. In living cells, NGF (10 ng/mL) had little effect on the FRET ratio, but robust increase in the FRET ratio was found by adding DCP-LA $(100 \mathrm{nM})$ (Fig. 4A). In fixed cells, little effect was found by solitary treatment with NGF $(10 \mathrm{ng} / \mathrm{mL})$ or DCP-LA (100 nM), but significant increase in the FRET ratio was induced by co-treatment with NGF and DCP-LA (Fig. 4B). This suggests that DCP-LA activates Rac1 by enhancing NGF signaling. In support of this, an increase in the 
Fig. 5. A schematic diagram for Rac1 activation pathway along a RTK/IRS-1/PI3K/PDK1/Akt/Rac1 axis. pY, tyrosine phosphorylation; pT, threonine phosphorylation; pS, serine phosphorylation.

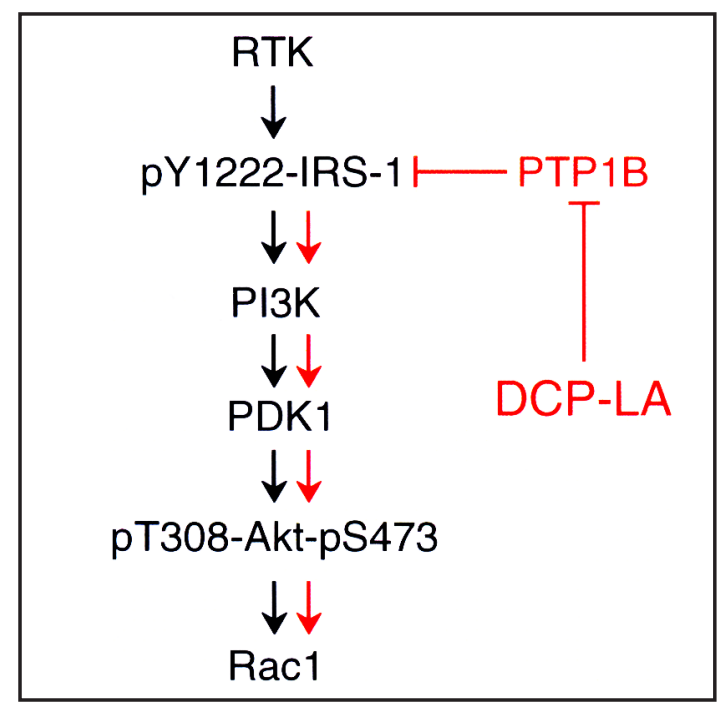

FRET ratio induced by NGF and DCP-LA was neutralized by the PI3K inhibitor wortmannin $(20 \mathrm{nM})$, the PDK1 inhibitor BX912 (100 nM), or the Akt inhibitor MK2206 (5 $\mu \mathrm{M})$ (Fig. 4B).

Intriguingly, a much higher concentration $(10 \mu \mathrm{M})$ of DCP-LA significantly increased the FRET ratio still in the absence of NGF both in living and fixed cells (Fig. 4C,D). An increase in the FRET ratio was still found with sodium orthovanadate $(10 \mu \mathrm{M})$ in living cells (Fig. 4C). Taken together, PTP1B inhibition, induced by DCP-LA or a PTP1B inhibitor, could activate Rac1. DCP-LA $(10 \mu \mathrm{M})$-induced increase in the FRET ratio was abrogated by wortmannin $(20$ nM), BX912 (100 nM), or MK2206 (5 $\mu$ M)(Fig. 4D). Overall, these results lead to a conclusion that PTP1B inhibition induced by DCP-LA could activate Rac1 by enhancing a RTK/IRS-1/ PI3K/PDK1/Akt/Rac1 pathway (Fig. 5).

\section{Discussion}

PTP1B is a prototypical member of the PTP family of protein tyrosine phosphatases and is ubiquitously expressed. PTP1B consists of the $\mathrm{N}$-terminal catalytic domain containing two aryl phosphate-binding sites: a high-affinity catalytic site and a low-affinity non-catalytic site [14]. The C-terminal domain of PTP1B is proline-rich, whereas the hydrophobic amino acid residues 400-435 contribute to location of the enzyme at the cytoplasmic face of the endoplasmic reticulum. The $\mathrm{C}$-terminal domain influences the $\mathrm{N}$-terminal domain by causing a global conformational change of PTP1B molecule that allows formation of direct contacts between the catalytic domain and the phosphorylated substrates [15]. PTP1B is implicated in the regulation of cell growth, differentiation, apoptosis, and cell movement [16]. So far have been provided a variety of PTP1B inhibitors. The most efficient inhibition is accomplished when the inhibitor occupies the high-affinity catalytic site of PTP1B. The site has preference for acidic residues, and therefore, inhibitors targeting the site should be anionic charged at physiologic $\mathrm{pH}$. Vanadate inhibits PTP1B by binding to the active site of the phosphatase enzyme, where vanadate forms a thiol-vanadyl ester linkage with the catalytic Cys 215 residue, similar to the covalent thiol-phosphate linkage formed during normal enzymatic catalysis [17]. New targets for PTP1B inhibitors are phosphotyrosine mimetics, which are highly anionic and display polar groups. These compounds can inhibit PTP1B by interacting with PTP1B active site [17]. Another group of PTP1B inhibitors bind to the secondary lowaffinity non-catalytic site of the enzyme demarcated by Arg24 and Arg254 [17].

One of the most striking findings in the present study is that a drastic inhibition of PTP1B was induced by DCP-LA. This, in the light of the fact that DCP-LA bound to PTP1B, suggests that DCP-LA inhibits PTP1B through its direct binding. A similar inhibition of 
PTP1B was found with the cis-unsaturated free fatty acid linoleic acid. In addition, we have found that other cis-unsaturated free fatty acids such as oleic and linolenic acid suppress PTP1B activity [18]. This raises the possibility that PTP1B has the binding site for DCP-LA or cis-unsaturated free fatty acids. We are currently attempting to determine the binding site in PTP1B for DCP-LA or cis-unsaturated free fatty acids using mutated PTP1B.

RTK constitutes a signaling pathway along a RTK/IRS-1/PI3K/PDK1/Akt/Rac1 axis $[12,13]$. RTK signal is initiated by tyrosine phosphorylation of its own receptor and IRS1. PTP1B downregulates RTK signal by dephosphorylating tyrosine phosphorylation of proteins; conversely, PTP1B inhibition upregulates RTK signal by preventing tyrosine dephosphorylation, allowing persistent phosphorylation of proteins. In the present study, DCP-LA enhanced NGF-stimulated phosphorylation of IRS-1 at Tyr1222 in PC-12 cells, although DCP-LA had no significant effect on NGF-stimulated phosphorylation of TrkA at Tyr490. This indicates that DCP-LA could enhance RTK signaling by inhibiting tyrosine dephosphorylation of IRS-1. Moreover, DCP-LA enhanced NGF-stimulated phosphorylation of Akt1/2 at Thr308/309 and Ser473/474 in PC-12 cells. Collectively, these results suggest that DCP-LA-induced PTP1B inhibition enhances Akt1/2 activation by stimulating an IRS-1/ PI3K/PDK1/Akt pathway.

Akt activates the small G-protein Rac1 as a downstream effector [12, 13]. In the FRET analysis using living and fixed PC-12 cells, co-treatment with NGF and a lower concentration $(100 \mathrm{nM})$ of DCP-LA significantly enhanced the FRET ratio, although solitary treatment with NGF or DCP-LA had little effect. An enhancement in the FRET ratio induced by NGF and DCPLA (100 nM) was prevented by the PI3K inhibitor wortmannin, the PDK1 inhibitor BX912, or the Akt inhibitor MK2206. This indicates that DCP-LA activates Rac1 by enhancing a RTK/IRS-1/PI3K/PDK1/Akt/Rac1 pathway in association with PTP1B inhibition. Notably, a higher concentration $(10 \mu \mathrm{M})$ of DCP-LA increased the FRET ratio still in the absence of NGF, and the effect was also abrogated by wortmannin, BX912, or MK2206. Taken together, these results indicate that DCP-LA inhibits PTP1B, possibly through its direct binding, leading to an enhancement in the RTK signaling along a RTK/IRS-1/PI3K/PDK1/Akt/Rac1 axis to activate Rac1. This represents the new action of DCP-LA in relation to PTP1B inhibition.

In summary, the results of the present study show that PTP1B inhibition, induced by the linoleic acid derivative DCP-LA, causes Rac1 activation by enhancing a RTK/IRS-1/PI3K/ Akt/Rac1 pathway (Fig. 5).

\section{References}

1 Kanno T, Yamamoto H, Yaguchi T, Hi R, Mukasa T, Fujikawa H, Nagata T, Yamamoto S, Tanaka A, Nishizaki T: The linoleic acid derivative DCP-LA selectively activates PKC- $\varepsilon$, possibly binding to the phosphatidylserine binding site. J Lipid Res 2006;47:1146-1156.

2 Shimizu T, Kanno T, Tanaka A, Nishizaki T: $\alpha, \beta$-DCP-LA selectively activates PKC- $\varepsilon$ and stimulates neurotransmitter release with the highest potency among 4 diastereomers. Cell Physiol Biochem 2011;27:149-158.

3 Tanaka A, Nishizaki T: The newly synthesized linoleic acid derivative FR236924 induces a long-lasting facilitation of hippocampal neurotransmission by targeting nicotinic acetylcholine receptors. Bioorg Med Chem Lett 2003;13:1037-1040.

4 Yamamoto S, Kanno T, Nagata T, Yaguchi T, Tanaka A, Nishizaki T: The linoleic acid derivative FR236924 facilitates hippocampal synaptic transmission by enhancing activity of presynaptic $\alpha 7$ acetylcholine receptors on the glutamatergic terminals. Neuroscience 2005;130:207-213.

5 Nagata T, Yamamoto S, Yaguchi T, Iso H, Tanaka A, Nishizaki T: The newly synthesized linoleic acid derivative DCP-LA ameliorates memory deficits in animal models treated with amyloid- $\beta$ peptide and scopolamine. Psychogeriatrics 205;5:122-126.

6 Yaguchi T, Nagata T, Mukasa T, Fujikawa H, Yamamoto H, Yamamoto S, Iso H, Tanaka A, Nishizaki T: Linoleic acid derivative DCP-LA improves learning impairment in SAMP8. Neuroreport 2006;17:105-108. 


\begin{tabular}{|c|c|c|}
\hline Cellular Physiology & Cell Physiol Biochem 2014;33:1097-1105 & \\
\hline and Biochemistry & $\begin{array}{l}\text { DOI: 10.1159/000358679 } \\
\text { Publisned online: April O9, } 2014\end{array}$ & $\begin{array}{l}\text { O } 2014 \text { S. Karger AG, Basel } \\
\text { www.karger.com/cpb }\end{array}$ \\
\hline
\end{tabular}

7 Nagata T, Tomiyama T, Mori H, Yaguchi T, Nishizaki T: DCP-LA neutralizes mutant amyloid $\beta$ peptideinduced impairment of long-term potentiation and spatial learning. Behav Brain Res 2010;206:151-154.

8 Kanno T, Yaguchi T, Nagata T, Tanaka A, Nishizaki T: DCP-LA stimulates AMPA receptor exocytosis through CaMKII activation due to PP-1 inhibition. J Cell Physiol 2009;221:183-188.

-9 Kanno T, Tsuchiya A, Shimizu T, Tanaka A, Nishizaki T: Indomethacin serves as a potential inhibitor of protein phosphatases. Cell Physiol Biochem 2012;30:1014-1022.

-10 Niwa H, Yamamura K, Miyazaki J: Efficient selection for high-expression transfectants with a novel eukaryotic vector. Gene 1991;108:193-199.

-11 Komatsu N, Aoki K, Yamada M, Yukinaga H, Fujita Y, Kamioka Y, Matsuda M: Development of an optimized backbone of FRET biosensors for kinases and GTPases. Mol Biol Cell 2011;22:4647-4656.

12 Niba ET, Nagaya H, Kanno T, Tsuchiya A, Gotoh A, Tabata C, Kuribayashi K, Nakano T, Nishizaki T: Crosstalk between PI3 kinase/PDK1/Akt/Rac1 and Ras/Raf/MEK/ERK pathways downstream PDGF receptor. Cell Physiol Biochem 2013;31:905-913.

13 Claesson-Welsh L, Welsh M: VEGFA and tumour angiogenesis. J Intern Med 2013:273:114-127.

14 Wang JF, Gong K, Wei DQ Li YX, Chou KC: Molecular dynamics studies on the interactions of PTP1B with inhibitors: from the first phosphate-binding site to the second one. Protein Eng Des Sel 2009;22:349-355.

15 Picha KM, Patel SS, Mandiyan S, Koehn J, Wennogle LP: The role of the C-terminal domain of protein tyrosine phosphatase-1B in phosphatase activity and substrate binding. J Biol Chem 2007;282:2911-2917.

16 Haj FG, Markova B, Klaman LD, Bohmer FD, Neel BG: Regulation of receptor tyrosine kinase signaling by protein tyrosine phosphatase-1B. J Biol Chem 2003;278:739-744.

17 Popov D: Novel protein tyrosine phosphatase 1B inhibitors: interaction requirements for improved intracellular efficacy in type 2 diabetes mellitus and obesity control. Biochem Biophys Res Commun 2011;410:377-381.

-18 Shibata E, Kanno T, Tsuchiya A, Kuribayashi K, Tabata C, Nakano T, Nishizaki T: Free fatty acids inhibit protein tyrosine phosphatase 1B and activate Akt. Cell Physiol Biochem 2013;32:871-879. 